\title{
Microsurgical Decompression of Trigeminal Neuralgia Caused by Simultaneous Double Arterial (SCA and AICA) and Petrosal Vein Complex Compression
}

\author{
Domagoj Gajski ${ }^{1,2,3}$ Alicia R. Dennis ${ }^{4}$ Kenan I. Arnautovićc ${ }^{4,5}$ \\ ${ }^{1}$ Department of Neurosurgery, University Hospital Center Sestre \\ Milosrdnice, Zagreb, Croatia \\ 2 Department of Anatomy and Physiology, University of Applied \\ Health Sciences, Zagreb, Croatia \\ ${ }^{3}$ School of Dental Medicine, University of Zagreb, Zagreb, Croatia \\ ${ }^{4}$ Semmes Murphey Neurologic and Spine Institute, Memphis, \\ Tennessee, United States \\ ${ }^{5}$ Department of Neurosurgery, University of Tennessee Health \\ Science Center, Memphis, Tennessee, United States
}

\author{
Address for correspondence Kenan I. Arnautović, MD, PhD, \\ Department of Neurosurgery, Semmes Murphey Neurologic and \\ Spine Institute, University of Tennessee Health Science Center, 6325 \\ Humphreys Belvedere, Memphis, TN 38120, United States \\ (e-mail: kenanarnaut@yahoo.com).
}

J Neurol Surg B 2018;79(suppl S5):S428-S430.

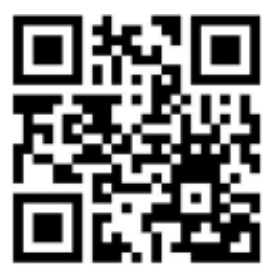

received

April 23, 2018

accepted

August 12, 2018

published online

September 25, 2018
Trigeminal neuralgia is a chronic pain disorder affecting the face. In approximately $80 \%$ of cases, it is most commonly caused, when the root entry zone (REZ) of the trigeminal nerve is compressed by the superior cerebellar artery (SCA). The etiology of the remaining $20 \%$ of cases is distributed among venous, arteriovenous malformations, posterior fossa tumors, multiple sclerosis plaque compressions, and other pathologies. Combinations of those compressive factors are very rare. ${ }^{1-4}$ Herein, we present a video clip of microvascular decompression (MVD) in a 73-year-old female, who has failed conservative treatment with 6 medications over 10 years. She was affected by a unique triple compression of the right REZ by the SCA, anterior inferior cerebellar artery (AICA), and petrosal vein complex ( - Fig. 1A). Right-sided microsurgical decompression of the REZ of the trigeminal nerve through standard retrosigmoid craniotomy was performed by the senior author (K.I.A.). The SCA and AICA were separated from the nerve using Teflon pledgets. The petrosal vein complex was coagulated and divided, freeing up the right trigeminal nerve (-Fig. 1B). The patient was discharged home on the third postoperative day with complete resolution of trigeminal neuralgia. The link to the Video can be found at: https://youtu.be/PYVvlmGW0yE. www.thieme.com/skullbasevideos

www.thieme.com/jnlsbvideos
License terms

(c) $(1) \$$ 10.1055/s-0038-1669968. ISSN 2193-6331. (c) 2018 Georg Thieme Verlag KG Stuttgart · New York 


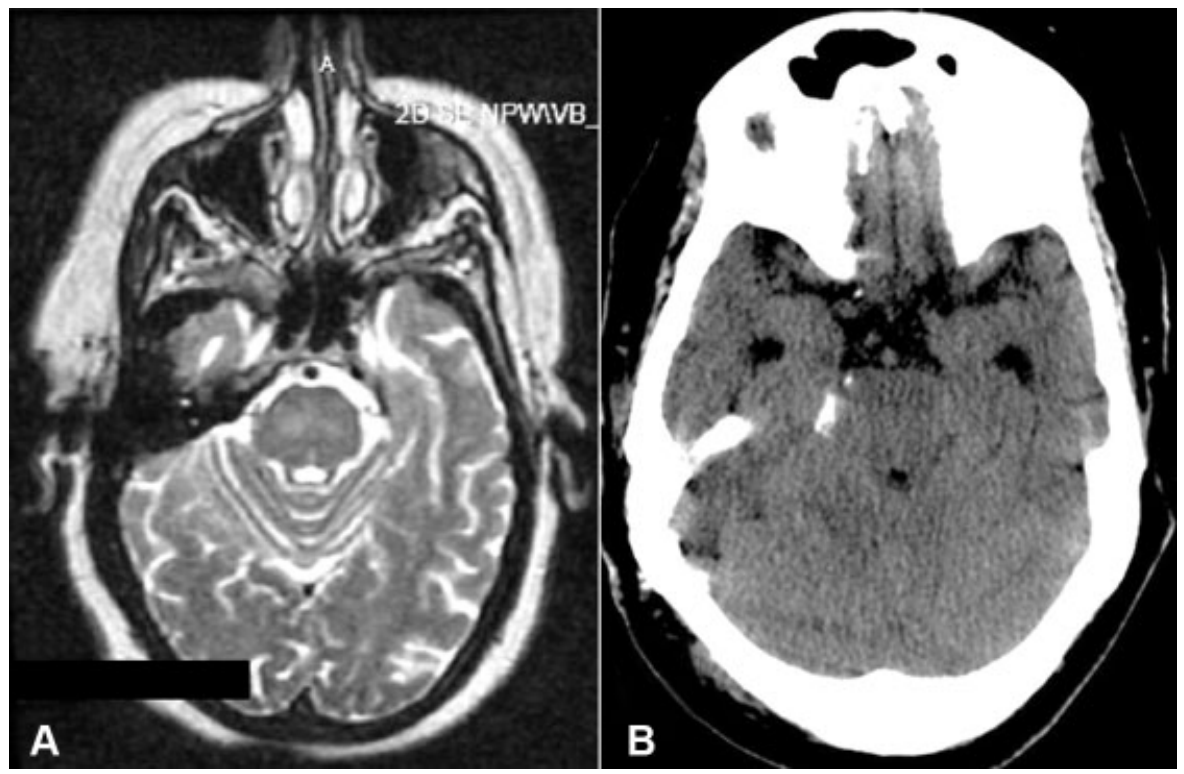

Fig. 1 (A) Preoperative T2-weighted axial magnetic resonance imaging (MRI); (B) Postoperative noncontrast axial computed tomography (CT) of brain.

\section{Conflict of Interest}

None.

\section{Acknowlegements}

No financial or material support was accepted as part of this study. The authors wish to thank Andrew J. Gienapp for copy editing, preparation of the manuscript, and figure for publishing, and publication assistance.

\section{References}

1 Jannetta PJ.Arterial compression of the trigeminal nerve at the pons in patients with trigeminal neuralgia.J Neurosurg 1967;26(01):159-162

2 Haines SJ, Jannetta PJ, Zorub DS. Microvascular relations of the trigeminal nerve. An anatomical study with clinical correlation. J Neurosurg 1980;52(03):381-386

3 Arnautovic KI, Husain MM, Linskey ME. Cranial nerve root entry zone primary cerebellopontine angle gliomas: a rare and poorly recognized subset of extraparenchymal tumors. J Neurooncol 2000; 49(03):205-212

4 Greenberg MS. Handbook of Neurosurgery. NY: Thieme; 2010 